Old Dominion University

ODU Digital Commons

Mechanical \& Aerospace Engineering Faculty

Publications

Mechanical \& Aerospace Engineering

2020

\title{
Parametric Study of a Turbojet Engine With Auxiliary Bypass Combustion- The TurboAux Engine
}

\author{
Kaleab Fetahi \\ Old Dominion University, kfeta001@odu.edu \\ Sharanabasaweshwara A. Asundi \\ Old Dominion University, sasundi@odu.edu \\ Arthur C. Taylor \\ Old Dominion University, ataylor@odu.edu
}

Adem H. Ibrahim

Syed Firasat Ali

Follow this and additional works at: https://digitalcommons.odu.edu/mae_fac_pubs

Part of the Aeronautical Vehicles Commons, and the Propulsion and Power Commons

\section{Original Publication Citation}

Fetahi, K., Asundi, S., Taylor, A., Ali, S. F., \& Ibrahim, A. (2020). Parametric study of a turbojet engine with auxiliary bypass combustion - The TurboAux engine. AIAA Propulsion and Energy 2020 Forum, Virtual Event, August 24-28, 2020.

This Conference Paper is brought to you for free and open access by the Mechanical \& Aerospace Engineering at ODU Digital Commons. It has been accepted for inclusion in Mechanical \& Aerospace Engineering Faculty Publications by an authorized administrator of ODU Digital Commons. For more information, please contact digitalcommons@odu.edu. 


\title{
Parametric Study of a Turbojet Engine with Auxiliary Bypass Combustion - The TurboAux Engine
}

\author{
Kaleab Fetahi ${ }^{1}$, Sharanabasaweshwara A. Asundi ${ }^{2}$, Arthur C. Taylor ${ }^{3}$ \\ Old Dominion University, Norfolk, Virginia, 23529, United States of America \\ Syed Firasat $\mathrm{Ali}^{4}$ \\ Tuskegee University, Tuskegee, Alabama, 36088, United States of America \\ Adem H. Ibrahim ${ }^{5}$ \\ Norfolk State University, Norfolk, VA, 23504, United States of America
}

\begin{abstract}
A parametric study of a novel turbojet engine with an auxiliary combustion chamber, nicknamed the TurboAux engine is presented. The TurboAux engine is conceived as an extension of a turbojet engine with an auxiliary bypass annular combustion chamber around the core stream. The study presented in this article is motivated by the need to facilitate clean secondary burning of fuel at temperatures higher than conventionally realized from air exiting the low-pressure compressor. The parametric study is initiated by performing a simple optimization analysis to identify optimal 'fan' pressure ratios for a series of conventional lowbypass turbofan engines with varying bypass ratios $(0.1$ to 1.5$)$. The fan pressure ratios for corresponding bypass ratios are chosen for studying varying configurations of the TurboAux engine. The article is presented in two phases - (i) Phase I presents the simulations carried out to arrive at an optimal configuration of a TurboAux engine and it formulation, (ii) Phase II presents simulations and results to compare the performance of a low-bypass turbofan engine to the TurboAux engine. The formulation and results are an attempt to make a case for charter aircrafts and efficient close-air-support aircrafts.
\end{abstract}

\section{Nomenclature}

$B \quad=$ bypass ratio

$C \quad=$ local speed of sound

$C_{p 0} \quad=$ specific heat at constant pressure

$f_{\text {actual }}=$ actual fuel to air ratio of core stream

$f_{\text {aux }}=$ actual fuel to air ratio of auxiliary stream

$f_{\text {ideal }}=$ ideal fuel to air ratio

$f_{0} \quad=$ overall actual fuel to air ratio of core and auxiliary streams

$\mathrm{H}_{r p \mathrm{CO} 2}=$ enthalpy of reaction of $\mathrm{CO}_{2}$

$H_{r p f} \quad=$ enthalpy of reaction of fuel

$\mathrm{HV} \quad=$ heating value of fuel

${ }^{1}$ Graduate Student, Mechanical and Aerospace Engineering, and AIAA Student Member.

${ }^{2}$ Assistant Professor, Mechanical and Aerospace Engineering, and AIAA Professional Member.

${ }^{3}$ Professor, Mechanical and Aerospace Engineering.

${ }^{4}$ Associate Professor, Aerospace Science Engineering, and AIAA Associate Member.

${ }^{5}$ Professor, Mechanical Engineering, and AIAA Associate Member. 


\begin{tabular}{|c|c|c|}
\hline$M_{a}$ & $=$ & flight speed \\
\hline$M_{\text {air }}$ & $=$ & molar mass of air \\
\hline$\dot{m}_{a u x}$ & $=$ & mass flow of auxiliary stream \\
\hline$\dot{m}_{\text {core }}$ & $=$ & mass flow of core stream \\
\hline$\dot{m}_{f 1}$ & $=$ & mass flow of fuel into core stream \\
\hline$\dot{m}_{f 2}$ & $=$ & mass flow of fuel into auxiliary stream \\
\hline$M_{\text {fuel }}$ & $=$ & molar mass of fuel \\
\hline$P_{0}$ & $=$ & stagnation pressure \\
\hline$P_{a}$ & $=$ & ambient static pressure \\
\hline$R$ & $=$ & specific gas constant \\
\hline$T_{0}$ & $=$ & stagnation temperature \\
\hline$T_{a}$ & $=$ & ambient static temperature \\
\hline$T_{p}$ & $=$ & static temperature of the products of combustion \\
\hline$T_{r}$ & $=$ & static temperature of the reactants of combustion \\
\hline$V_{a}$ & $=$ & velocity of air at inlet \\
\hline$w_{C H P}$ & $=$ & specific work required to drive high-pressure compressor \\
\hline$w_{C L P}$ & $=$ & specific work required to drive low-pressure compressor \\
\hline$Y_{c c}$ & $=$ & moles of air required for stoichiometric combustion \\
\hline$\gamma$ & $=$ & ratio of specific heat at constant pressure to specific heat at constant volume \\
\hline$\eta_{b}$ & $=$ & burner efficiency \\
\hline$\eta_{c}$ & $=$ & compressor efficiency \\
\hline$\eta_{d}$ & $=$ & diffuser efficiency \\
\hline$\eta_{m}$ & $=$ & mechanical efficiency \\
\hline$\eta_{n}$ & $=$ & nozzle efficiency \\
\hline$\eta_{o}$ & $=$ & overall efficiency \\
\hline$\eta_{p}$ & $=$ & propulsive efficiency \\
\hline$\eta_{t}$ & $=$ & turbine efficiency \\
\hline$\eta_{\text {th }}$ & $=$ & thermal efficiency \\
\hline$\pi_{c}$ & $=$ & overall pressure ratio \\
\hline$\pi_{H P}$ & $=$ & high-pressure compressor pressure ratio \\
\hline$\pi_{L P}$ & $=$ & low-pressure compressor pressure ratio \\
\hline
\end{tabular}

\section{Introduction}

Conventional turbojet engines have one stream, which passes through the core of the engine without bypassing any of the components. The core stream is compressed through the various stages of the compressor prior to combustion, then after combustion, is expanded through the various stages of the turbine prior to exhausting through a nozzle. The core stream, after the combustion stage, has a considerable increase in its thermal and kinetic energy. In current operational engines, there are strict limitations on the temperature that the turbine blades can withstand. Temperatures in excess of $1950 \mathrm{~K}$ can cause the thin blades of a turbine to melt, which may damage the engine $[1,2]$. These limitations manifest in the potential thrust capability of an engine. To overcome these limitations, a turbojet engine with an auxiliary bypass combustion chamber, nicknamed TurboAux engine, is conceived and presented as a parametric study in this paper. The parametric study is initiated by performing a simple optimization analysis to identify optimal 'fan' pressure ratios for a series of conventional turbofan engines with varying bypass ratios. The fan pressure ratios (FPRs) for corresponding bypass ratios are chosen for studying varying configurations of the TurboAux engine. This research analyzes the viability of an auxiliary bypass combustion system that could mitigate the issues with efficient energy production. The auxiliary combustion chamber would use oxygen-rich air coming from the lowpressure compressor (LPC) to feed the secondary combustion process instead of just bypassing the engine. The article is organized as follows. A schematic layout and the description of the TurboAux engine are presented in Section III. The simulations carried out to arrive at an optimal configuration of a TurboAux engine are presented in Section IV and the formulation is presented in Section V. The simulations, results to compare the performance of varying configurations of the TurboAux engine to a conventional low-bypass turbofan engine are presented in Section V. As part of this section, the results are used to discuss a case for the TurboAux engine to be used in charter aircrafts and other aircraft with similar engines. 


\section{Configuration of the TurboAux Engine}

A schematic layout of the configuration of the TurboAux engine is shown in Fig. 1. Airflow will enter the inlet of the diffuser of the engine, and the stream will be compressed by the LPC and then the high-pressure compressor (HPC). After the LPC stage, the stream will diverge into two streams where one stream will enter the HPC for further compression and will be ignited in the main combustion chamber while the other stream will bypass the HPC and enter the auxiliary bypass combustion chamber. This stream will also bypass the main combustion chamber and the turbine. The core stream, after exiting the main combustion chamber, will outlet into the various stages of the turbine, which will power the compressors. The bypass stream, upon ignition in the auxiliary combustion chamber will reunite and mix with the core stream prior to exhausting through a common nozzle. Since the auxiliary combustion chamber will not exhaust its hot gases into the turbine, it is free of the temperature limitations that the core stream will experience to avoid damaging the thin blades of the turbine. The bypass stream is an oxygen-rich stream, which will allow for "clean" burning at temperatures in excess of $2500 \mathrm{~K}$. The raising of the temperature of the products of this auxiliary combustion chamber is believed to lead to an increase in the efficiency of the engine

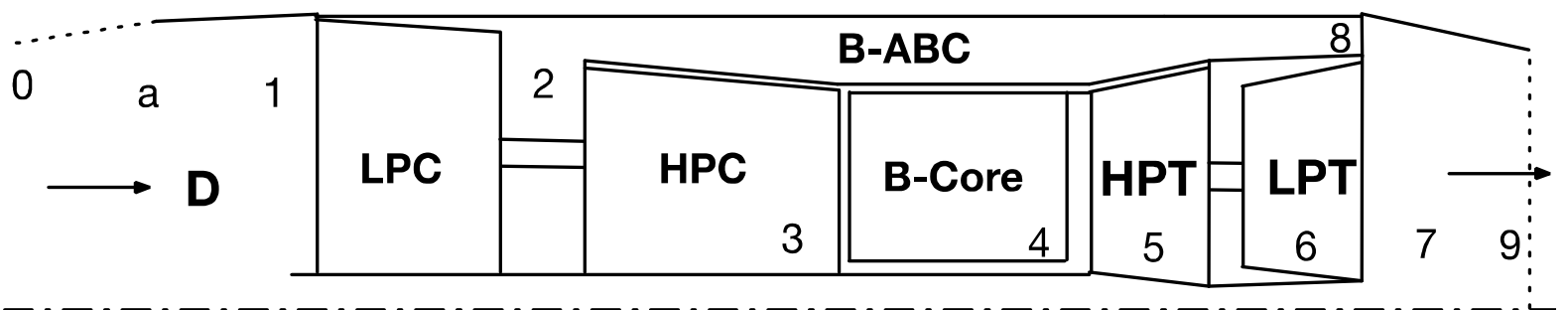

0-1: Free Stream to Engine Entrance

a-1: Diffuser (D)

1-2: Low Pressure Compressor (LPC)

2-3: High Pressure Compressor (HPC)

2-8: Auxiliary Bypass Combustion Burner (B-ABC)
3-4: Core Burner (B-Core)

4-5: High Pressure Turbine (HPT)

5-6: Low Pressure Turbine (LPT)

6\&8-7: Mixing

7-9: Single Converging Nozzle (Core+ABC)

Fig. 1 Schematic Layout of the Turbojet Engine with Auxiliary Bypass Combustion: TurboAux Engine

\section{Optimization Analysis to Identify Ideal Fan Pressure (LPC) Ratio}

An optimization analysis on a conventional turbofan engine was conducted to identify an optimal FPR and bypass ratio configuration [3], which would be adopted as the auxiliary bypass pressure ratio (ABPR) for the auxiliary bypass combustion chamber of the TurboAux engine. The results of these simulations are summarized in Fig. 2. As part of this optimization analysis, the overall pressure ratio (OPR) and the turbine inlet temperature were maintained constant for a range of bypass ratios of a conventional turbofan engine. For each configuration of the turbofan engine, the fan pressure ratio was varied from 1.3 to 7 and the thrust specific fuel consumption (TSFC) along with the specific thrust (Fs) were computed as shown in Fig. 2. For each bypass ratio, the results of the analysis yielded an optimal fan pressure ratio, where the TSFC was minimized and Fs was maximized, simultaneously. The optimal FPR thus identified was used as the auxiliary bypass pressure ratio of the TurboAux engine.
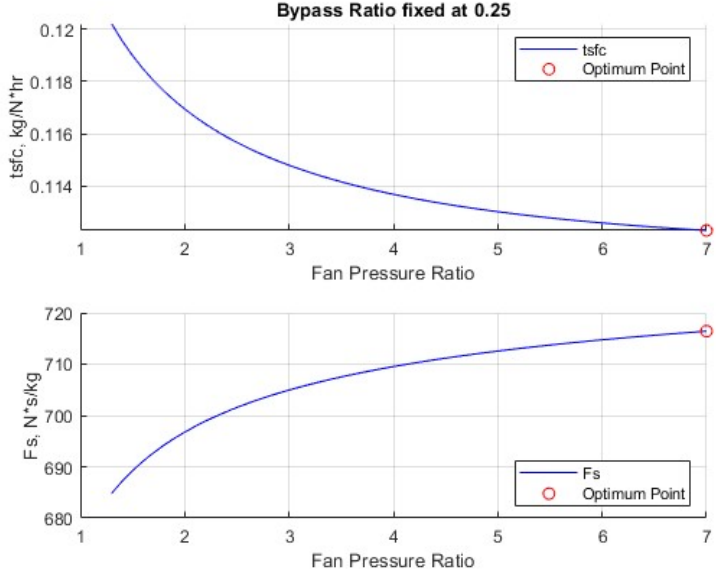
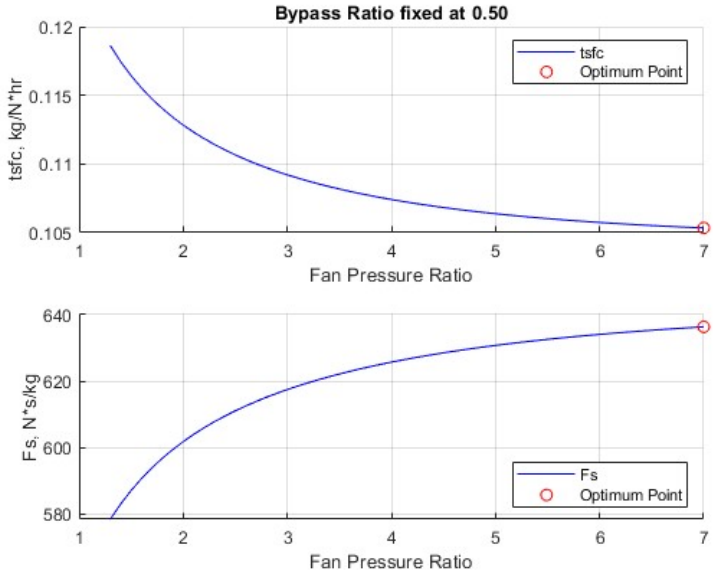

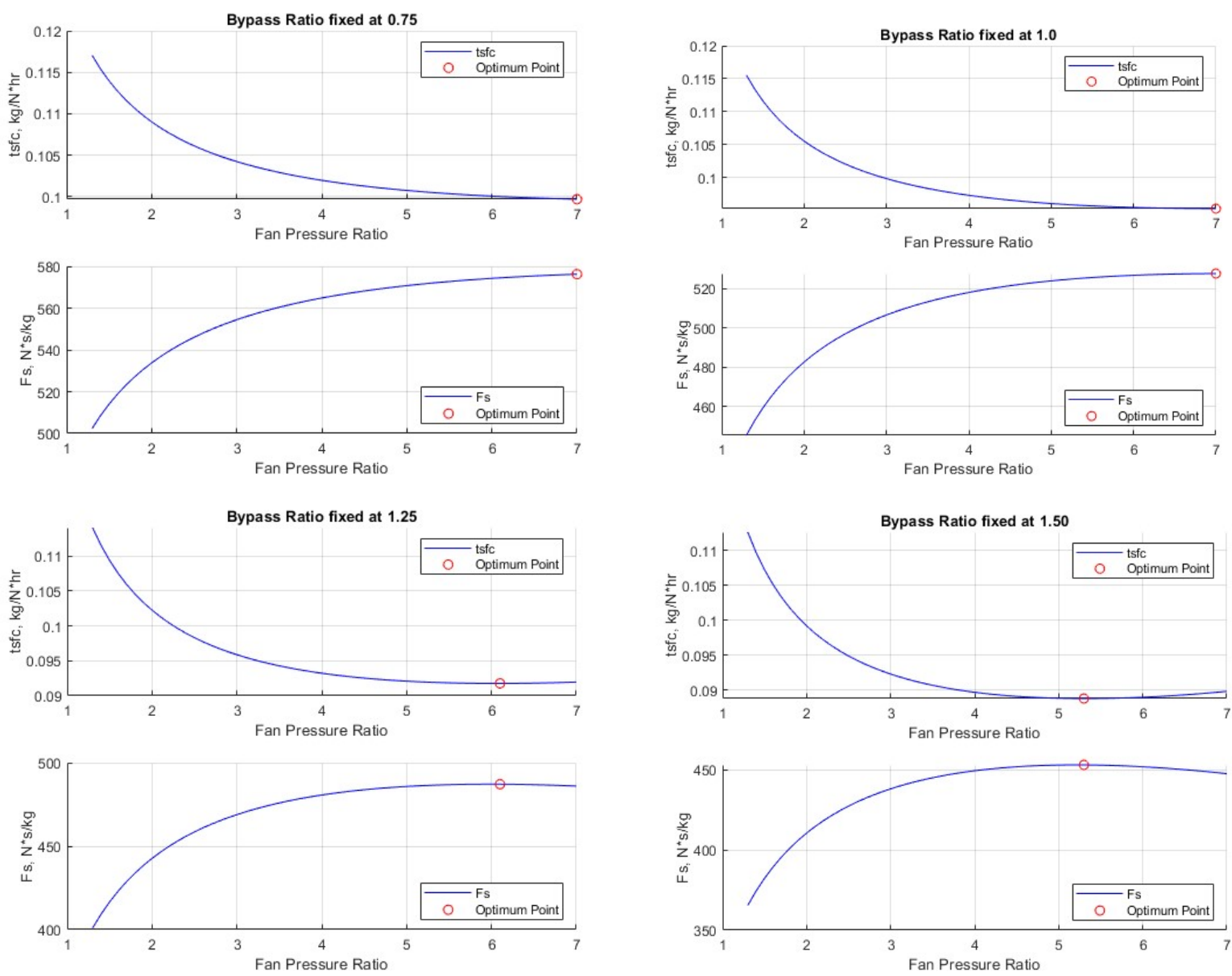

Fig. 2 Optimization Analysis to Identify Optimal Pressure Ratio Corresponding to a Bypass Ratio

\section{Formulation}

This section is a presentation of the mathematical formulation and calculations performed in the computer program to arrive at the results presented in the next section. Flight conditions and other simulation parameters and properties were selected to coincide with current flight conditions of similar engines and are summarized in Table 1.

Table 1. Simulation Parameters and Flight Conditions.

\begin{tabular}{cccc}
\hline Flight conditions: & $\mathrm{Ma}=0.84$ & $\mathrm{~Pa}=54.05 \mathrm{kPa}$ & $\mathrm{T}_{\mathrm{a}}=255.7 \mathrm{~K}$ \\
\hline Air properties: & $\mathrm{C}_{\mathrm{p} \text { 0air }}=1004.5 \mathrm{~J} / \mathrm{kg} * \mathrm{~K}$ & $\gamma_{\text {air }}=1.4$ & $\mathrm{R}_{\text {air }}=287 \mathrm{~J} / \mathrm{kg} * \mathrm{~K}$ \\
\hline Gas properties: & $\mathrm{C}_{\mathrm{p} 0 \text { gas }}=1148 \mathrm{~J} / \mathrm{kg} * \mathrm{~K}$ & $\gamma_{\mathrm{gas}}=1.3333$ & $\mathrm{R}_{\text {gas }}=287 \mathrm{~J} / \mathrm{kg} * \mathrm{~K}$ \\
\hline Other parameters: & $\mathrm{T}_{04}=1922 \mathrm{~K}$ & $\mathrm{~T}_{08}=2516 \mathrm{~K}$ & $\pi_{\mathrm{c}}=50$ \\
\hline Efficiencies: & $\eta_{\mathrm{d}}=0.93$ & $\eta_{\mathrm{c}}=0.93$ & $\eta_{\mathrm{b}}=0.98$ \\
\hline Fuel properties: & $\eta_{\mathrm{m}}=0.99$ & $\eta_{\mathrm{t}}=0.90$ & $\eta_{\mathrm{n}}=0.95$ \\
\hline & $\mathrm{H}_{\mathrm{rpf}}=-8561991.6 \mathrm{~kJ} / \mathrm{kmol}$ & $\mathrm{M}_{\text {fuel }}=197.7 \mathrm{kmol} / \mathrm{kg}$ & $\mathrm{HV}=43308000 \mathrm{~J} / \mathrm{kg}$ \\
\hline Moles of Carbon $(\mathrm{MC})=14.4$ & $\begin{array}{c}\text { Moles of Hydrogen } \\
(\mathrm{MH})=24.9\end{array}$ & $\begin{array}{c}\text { Moles of Oxygen } \\
(\mathrm{MO})=0\end{array}$ \\
\hline Other properties: & $\mathrm{H}_{\mathrm{rpCO} 2}=282800 \mathrm{~kJ} / \mathrm{kmol}$ & $\mathrm{M}_{\text {air }}=28.97 \mathrm{kmol} / \mathrm{kg}$ & \\
\hline
\end{tabular}


The local speed of sound and the flow speed at the inlet of the of the diffuser are computed in Eqs. (1) and (2), respectively. Upon entering the diffuser, the stream is slowed down and the new stagnation temperature and pressure of the stream due to the reduction in velocity and diffuser efficiency are calculated in Eqs. (3) and (4), respectively.

$$
\begin{gathered}
\mathrm{C}=\sqrt{\gamma_{\mathrm{a}} \cdot \mathrm{R}_{\mathrm{a}} \cdot \mathrm{T}_{\mathrm{a}}} \\
\mathrm{V}_{\mathrm{a}}=\mathrm{M}_{\mathrm{a}} \cdot \mathrm{C} \\
\mathrm{T}_{01}=\mathrm{T}_{\mathrm{a}}\left[1+\left(\frac{\gamma_{\mathrm{a}}-1}{2} \cdot \mathrm{M}_{\mathrm{a}}^{2}\right)\right] \\
\mathrm{P}_{01}=\mathrm{P}_{\mathrm{a}}\left[1+\eta_{\mathrm{d}} \cdot\left(\frac{\gamma_{\mathrm{a}}-1}{2}\right) \cdot \mathrm{M}_{\mathrm{a}}^{2}\right]^{\frac{\gamma_{\mathrm{a}}}{\gamma_{\mathrm{a}}-1}}
\end{gathered}
$$

After the diffuser, the flow is compressed by the LPC or "fan". The stagnation pressure is simply found as the product of the pressure ratio across the fan (FPR). The optimum FPR value from the optimized design is used here in Eq. (5). The stagnation temperature is computed in Eq. (6) which accounts for the efficiency of the compressor and the specific work required to operate the LPC is computed in Eq. (7).

$$
\begin{gathered}
P_{02}=P_{01} \cdot \pi_{L P} \\
T_{02}=T_{01}+\left\{\frac{T_{01}\left[\left(\pi_{L P}^{\frac{\gamma a-1}{\gamma a}}\right)-1\right]}{\eta_{c}}\right\} \\
W_{C}^{L P}=(B+1) \cdot C_{p 0 a} \cdot\left(T_{01}-T_{02}\right)
\end{gathered}
$$

Following the compression of the stream in the LPC, the stream diverges into two streams: the core stream and the auxiliary stream. The bypass ratio is defined in Eq. (8). The auxiliary stream bypasses the core of the engine and enters the auxiliary combustion chamber, while the core stream is compressed further through the stages of the HPC. The combustion process of the auxiliary combustion chamber will produce products at a temperature of $2516 \mathrm{~K}$. The loss in stagnation pressure in this combustion process is calculated in Eq. (9).

$$
\begin{gathered}
B=\frac{\dot{m}_{\text {aux }}}{\dot{m}_{\text {core }}} \\
P_{08}=P_{02} \cdot\left(\eta_{b}\right)
\end{gathered}
$$

The compression ratio of the HPC is calculated in Eq. (10) as the overall pressure ratio divided by the FPR. The stagnation pressure, stagnation temperature, and specific work required to operate the HPC are computed in similar manner as in the LPC in Eqs. (11), (12), and (13) respectively.

$$
\begin{gathered}
\pi_{H P}=\frac{\pi_{C}}{\pi_{L P}} \\
P_{03}=P_{02} \cdot \pi_{H P} \\
T_{03}=T_{02}+\left\{\frac{T_{02}\left[\left(\pi_{H P}^{\frac{\gamma a-1}{\gamma a}}\right)-1\right]}{\eta_{c}}\right\} \\
W_{C}^{H P}=C_{p 0 a} \cdot\left(T_{01}-T_{02}\right)
\end{gathered}
$$


The combustion process is assumed as a complete combustion process with excess air in the products and was modeled in both the auxiliary and main combustion chambers using the enthalpy of reactions, enthalpy of combustion, and the first law of thermodynamics. Equations (14) and (15) are equations used calculate the specific enthalpy, on a molar basis, of each constituent in the combustion process. The constants $a, b$, and $c$ are experimental coefficients taken from literature used in the calculation of the specific enthalpy [5]. Equation (16) calculates the change in the specific enthalpy. Due to temperature limitations of the turbine blades, the products of combustion from the main combustion chamber are exiting at $1922 \mathrm{~K}$. The number of moles for stoichiometric combustion of the fuel is computed in Eq. (17), and with the fuel, temperature of the reactants, and the temperature of the products specified, the number of moles of air required for complete combustion with excess air in the products is calculated in Eq. (18).

$$
\begin{gathered}
\bar{h}_{T r}=a+b \cdot \operatorname{Tr}+c \cdot \ln (T r) \\
\bar{h}_{T p}=a+b \cdot T p+c \cdot \ln (T p) \\
\Delta \bar{h}=\bar{h}_{T p}-\bar{h}_{T r} \\
Y_{c c}=M C+\left(\frac{M H}{4}\right)-\left(\frac{M O}{2}\right) \\
y=\frac{-H r p_{f}-(M C) \Delta \bar{h}_{C O_{2}}-\left(\frac{M H}{2}\right) \Delta \bar{h}_{H_{2} O}+\left(Y_{C c}\right) \Delta \bar{h}_{C O_{2}}}{(3.76) \Delta \bar{h}_{N_{2}}+\Delta \bar{h}_{O_{2}}}
\end{gathered}
$$

After the number of moles of air required for complete combustion is calculated in Eq. (18), Eq. (19) computes the ideal fuel to air ratio on a mass basis. To account for non-ideal combustion, the actual fuel to air ratios for both the main combustion chamber and the auxiliary combustion chamber are computed in Eqs. (20) and (21) respectfully. Losses in stagnation pressure due to friction and combustion are calculated in Eq. (22). Conservation of mass states that the total mass flow rate of fuel is the sum of the separate mass flow rates in Eq. (23). Using the bypass ratio, the overall fuel to air ratio of the entire engine accounting for both combustion processes is calculated in Eq. (24).

$$
\begin{gathered}
f_{\text {ideal }}=\left(\frac{1}{4.76 \cdot y}\right)\left(\frac{M_{\text {fuel }}}{M_{\text {air }}}\right) \\
f_{\text {actual }}=\frac{f_{\text {ideal }}}{\eta_{b}}=\frac{\dot{m}_{f 1}}{\dot{m}_{\text {core }}} \\
f_{\text {aux }}=\frac{f_{\text {ideal }}}{\eta_{b}}=\frac{\dot{m}_{f 2}}{\dot{m}_{\text {aux }}} \\
P_{04}=P_{03} \cdot\left(\eta_{b}\right) \\
\dot{m}_{f \text { tot }}=\dot{m}_{f 1}+\dot{m}_{f 2} \\
f_{o}=\left(\frac{B \cdot f_{\text {aux }}}{B+1}\right)\left(\frac{f_{\text {actual }}}{B+1}\right)=\frac{\dot{m}_{\text {ftot }}}{\dot{m}_{\text {core }}}
\end{gathered}
$$

Upon exiting the main combustion chamber, the core stream will be expanded through the high-pressure turbine and the low-pressure turbine. Equations (25) and (26) calculate the stagnation temperature and pressure exiting the high-pressure turbine and entering the low-pressure turbine. Similarly, Eqs. (27) and (28) calculate the stagnation temperature and pressure exiting the low-pressure turbine. Losses which occur due to the mechanical and component efficiency of the turbine are accounted for in these equations as well.

$$
T_{05}=T_{04}+\left[\frac{w_{C}^{H P}}{\eta_{m}\left(1+f_{\text {actual }}\right) \cdot C_{p 0 g}}\right]
$$




$$
\begin{aligned}
& P_{05}=P_{04}\left\{1-\left[\frac{1-\left(\frac{T_{05}}{T_{04}}\right)}{\eta_{t}}\right]\right\}^{\frac{\gamma_{g}}{\gamma_{g}-1}} \\
& T_{06}=T_{05}+\left[\frac{W_{C}^{L P}}{\eta_{m}\left(1+f_{\text {actual }} \cdot C_{p 0 g}\right.}\right] \\
& P_{06}=P_{05}\left\{1-\left[\frac{1-\left(\frac{T_{06}}{T_{05}}\right)}{\eta_{t}}\right]\right\}^{\frac{\gamma_{g}}{\gamma_{g}-1}}
\end{aligned}
$$

After the stages of the turbine, the core stream and the auxiliary stream will reunite and mix prior to exhausting through the nozzle. In Eq. (29), the stagnation temperature of the mixed streams in calculated by manipulating conservation of energy, conservation of mass, and the first law of thermodynamics. Similarly, in Eq. (30), the stagnation pressure is a mass-weighted average of the two streams mixing.

$$
\begin{aligned}
& T_{07}=\frac{B\left(1+f_{\text {aux }}\right) T_{08}+\left(1+f_{\text {actual }}\right) T_{06}}{B\left(1+f_{\text {aux }}\right)+\left(1+f_{\text {actual }}\right)} \\
& P_{07}=\frac{B\left(1+f_{\text {aux }}\right) P_{08}+\left(1+f_{\text {actual }}\right) P_{06}}{B\left(1+f_{\text {aux }}\right)+\left(1+f_{\text {actual }}\right)}
\end{aligned}
$$

Once the two streams have mixed into one, the new stream will exit through a converging nozzle. In Eq. (31), a ratio is set up to test if the nozzle is choked. If $\mathrm{P}^{*} / \mathrm{P}_{07}$ is greater than or equal to $\mathrm{P}_{\mathrm{a}} / \mathrm{P}_{07}$, then the nozzle is choked meaning the Mach number at the exit is 1. Subsequently, Eqs. (32) to (35) calculate the exit flow static pressure, static temperature, density, and velocity, respectively.

$$
\begin{gathered}
\frac{P^{*}}{P_{07}}=\left\{1-\frac{1}{\eta_{N}}\left[1-\left(\frac{2}{\gamma_{g}-1}\right)\right]\right\}^{\frac{\gamma_{g}}{\gamma_{g}-1}} \\
P_{e}=P_{07}\left(\frac{P^{*}}{P_{07}}\right) \\
T_{e}=T_{07}\left(\frac{2}{\gamma_{g}+1}\right) \\
\rho_{e}=\frac{P_{e}}{R_{g} \cdot T_{e}} \\
V_{e}=M_{e} \sqrt{\gamma_{g} \cdot R_{g} \cdot T_{e}}
\end{gathered}
$$

Conversely, if $\mathrm{P}^{*} / \mathrm{P}_{07}$ is less than or equal to $\mathrm{P}_{\mathrm{a}} / \mathrm{P}_{07}$, then the nozzle is not choked. This means that the exit pressure is equal to the ambient pressure. The exit flow conditions for the static temperature, density, Mach number, and velocity are calculated in Eqs. (36) to (39).

$$
\begin{gathered}
T_{e}=T_{07}\left\{1-\eta_{N}\left[1-\left(\frac{P_{e}}{P_{07}}\right)^{\left.\frac{\gamma_{g}-1}{\gamma_{g}}\right]}\right\}\right. \\
\rho_{e}=\frac{P_{e}}{R_{g} \cdot T_{e}} \\
M_{e}=\sqrt{\left[\left(\frac{T_{07}}{T_{e}}\right)-1\right]\left(\frac{2}{\gamma_{g}+1}\right)} \\
V_{e}=M_{e} \sqrt{\gamma_{g} \cdot R_{g} \cdot T_{e}}
\end{gathered}
$$


The last step of this parametric study is to calculate the performance and efficiency of this engine. Equations (40) and (41) calculate Fs and TSFC. In Eq. (42), the heating value of the fuel is converted from $\mathrm{kJ} / \mathrm{kmol}$ to J/kg. Lastly, Eqs. (43) to (45) are used to calculate the propulsive, thermal, and overall efficiency, respectively. Conventionally, propulsive efficiency is defined as the ratio of thrust power to the rate of addition of kinetic energy, and thermal efficiency is defined as the ratio of the rate of addition of kinetic energy to the rate of total energy consumption. These are approximations that neglect to account for the rate of addition of pressure energy [6]. Since the TurboAux is utilizing a purely converging nozzle which has choked flow in every case studied, the pressure energy is not negligible. It was necessary to adjust the conventional equations for propulsive and thermal efficiency to account for the increase in pressure energy. This is outlined in Eqs. (43) and (44).

$$
\begin{gathered}
F_{S}=\left[\left(1+f_{o}\right) V_{e}-V_{a}\right]+\left[\left(P_{e}-P_{a}\right)\left(\frac{1+f_{o}}{\rho_{e} \cdot V_{e}}\right)\right] \\
T S F C=\frac{3600 \cdot f_{o}}{F_{S}} \\
H V=\frac{-H r p_{f} \cdot 1000}{M_{f u e l}} \\
\eta_{\text {prop }}=\frac{F_{S} \cdot V_{a}}{\left[\left(1+f_{o}\right) \frac{V_{e}{ }^{2}}{2}-\frac{V a^{2}}{2}\right]+\left[\left(P_{e}-P_{a}\right)\left(\frac{1+f_{o}}{\rho_{e} \cdot V_{e}}\right)\right]^{2}} \\
\eta_{t h}=\frac{\left[\left(1+f_{o}\right) \frac{V_{e}^{2}}{2}-\frac{V a}{2}\right]+\left[\left(P_{e}-P_{a}\right)\left(\frac{1+f_{o}}{\rho_{e} \cdot V_{e}}\right)\right]^{2}}{f_{o} \cdot H V} \\
\eta_{o}=\eta_{\text {prop }} \cdot \eta_{t h}=\frac{F_{s} \cdot V_{a}}{f_{o} \cdot H V}
\end{gathered}
$$

\section{Simulation, Results and Discussion}

With the intent to evaluate performance, the thermodynamics of the low-bypass turbofan and the TurboAux engine were modeled and simulated with the use of a computer program. The engines were analyzed under the scenario where the optimal combinations of the FPRs and bypass ratios were adopted for each configuration. The simulations were carried out to understand which conditions provided optimal performances with respect to minimizing the increase in TSFC while aiming to maximize the increase in Fs. The performance of the engines is summarized in Figs. 3 and 4 and the values are tabulated in Tables 2 and 3. Table 4 tabulates the respective increases and decreases in the different performance parameters of both the low-bypass turbofan and the TurboAux. Figure 5 illustrates the changes in Fs and TSFC of both the TurboAux and a similarly configured low-bypass turbofan with respect to bypass ratio.

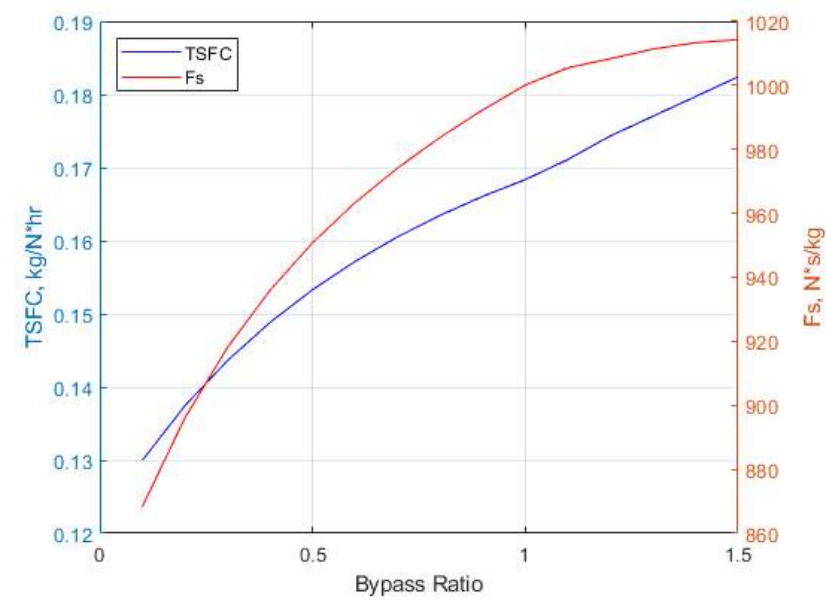

(a)

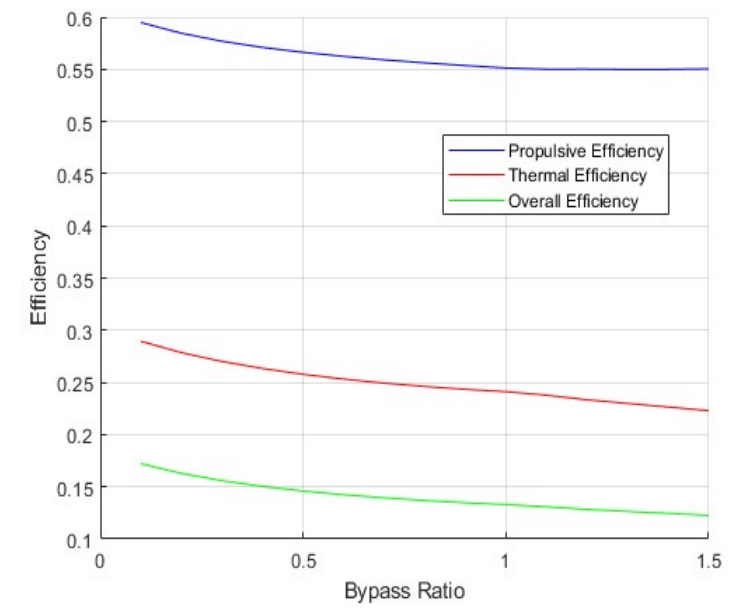

(b)

Fig. 3 Performance Analysis - (a) TurboAux: TSFC Vs Fs as a Function of Bypass Ratio, (b) TurboAux: Efficiency Vs Bypass Ratio 


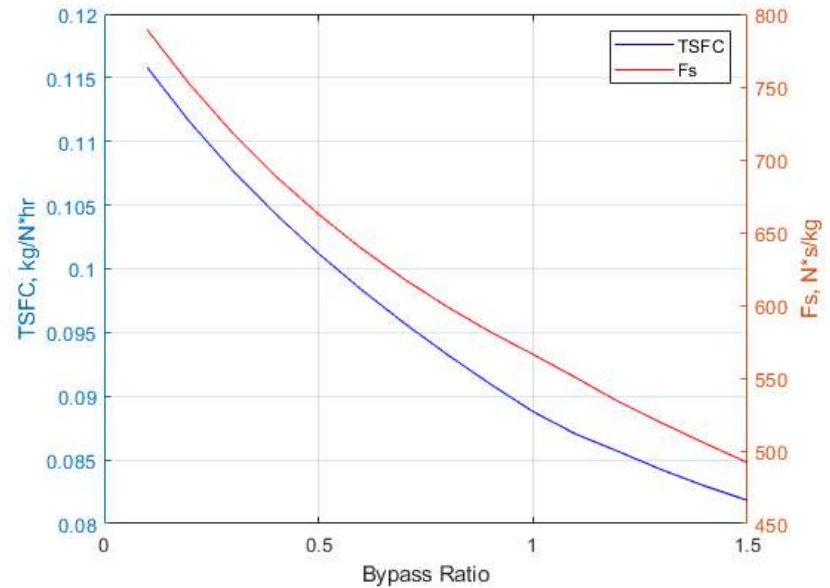

(a)

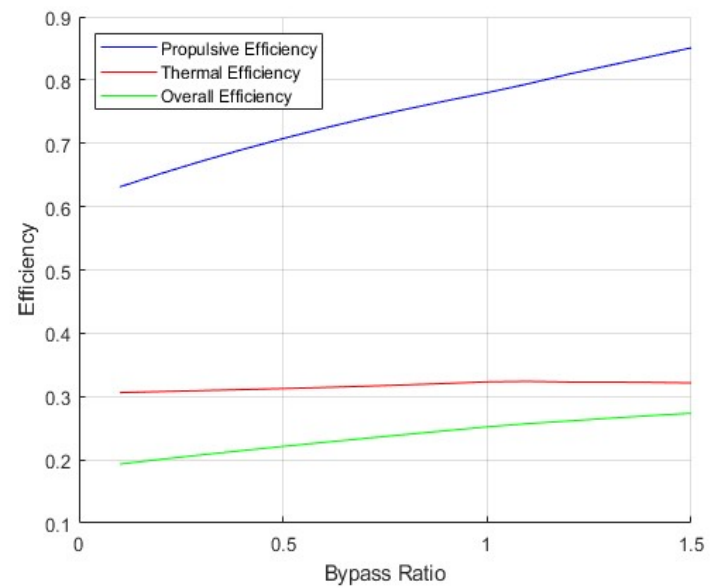

(b)

Fig. 4 Performance Analysis - (a) Turbofan: TSFC Vs Fs as a Function of Bypass Ratio, (b) Turbofan: Efficiency Vs Bypass Ratio

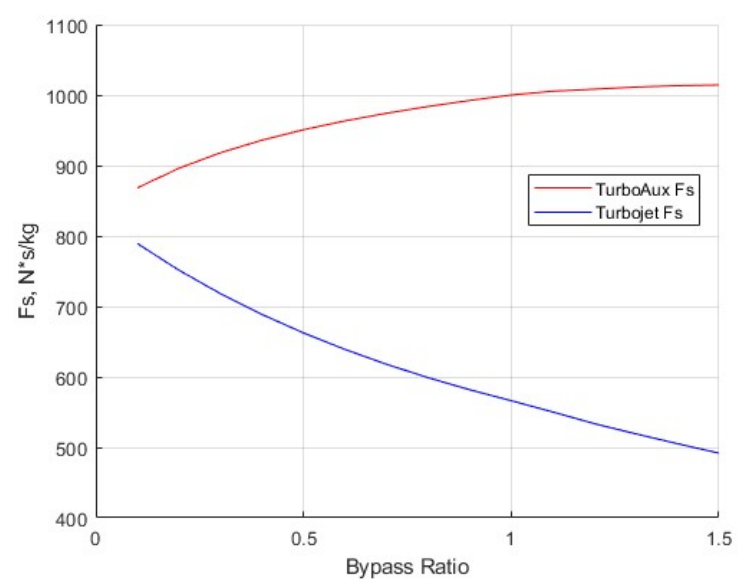

(a)

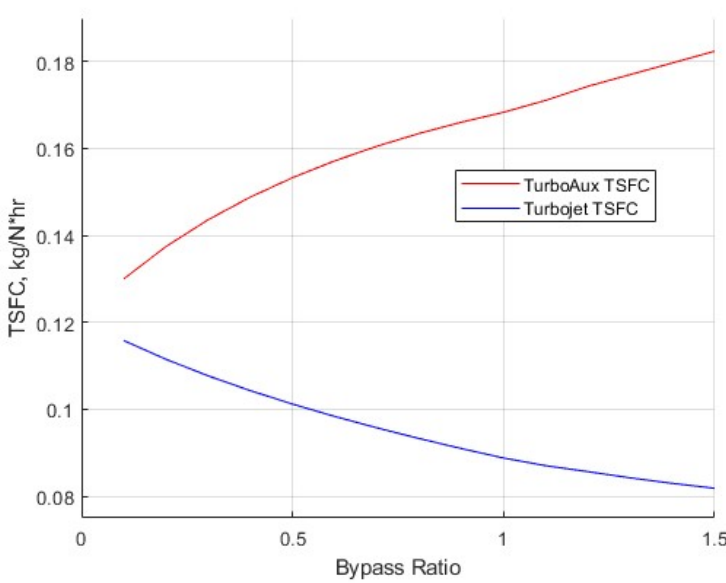

(b)

Fig. 5 Performance Analysis - (a) TurboAux Fs vs Turbofan Fs as a Function of Bypass Ratio, (b) TurboAux TSFC vs Turbofan TSFC Fs as a Function of Bypass Ratio

Table 2. Optimized Turbofan Engine Configuration and Corresponding Results

\begin{tabular}{ccccccc}
\hline Bypass Ratio & ABPR & $\begin{array}{c}\text { TSFC } \\
(\mathrm{kg} / \mathrm{N} * \mathrm{hr})\end{array}$ & $\begin{array}{c}\text { Fs } \\
(\mathrm{N} * \mathrm{~s} / \mathrm{kg})\end{array}$ & $\begin{array}{c}\text { Propulsive } \\
\text { Efficiency }\end{array}$ & $\begin{array}{c}\text { Thermal } \\
\text { Efficiency }\end{array}$ & $\begin{array}{c}\text { Overall } \\
\text { Efficiency }\end{array}$ \\
\hline 0.1 & 7 & 0.115819 & 789.260 & $63.12 \%$ & $30.61 \%$ & $19.32 \%$ \\
\hline 0.2 & 7 & 0.111510 & 751.444 & $65.21 \%$ & $30.78 \%$ & $20.07 \%$ \\
\hline 0.3 & 7 & 0.107705 & 718.150 & $67.17 \%$ & $30.94 \%$ & $20.78 \%$ \\
\hline 0.4 & 7 & 0.104294 & 688.660 & $69.02 \%$ & $31.09 \%$ & $21.46 \%$ \\
\hline 0.5 & 7 & 0.101199 & 662.408 & $70.76 \%$ & $31.26 \%$ & $22.12 \%$ \\
\hline
\end{tabular}




\begin{tabular}{ccccccc}
\hline 0.6 & 7 & 0.098359 & 638.937 & $72.39 \%$ & $31.43 \%$ & $22.75 \%$ \\
\hline 0.7 & 7 & 0.095729 & 617.874 & $73.93 \%$ & $31.62 \%$ & $23.38 \%$ \\
\hline .8 & 7 & 0.093274 & 598.906 & $75.37 \%$ & $31.84 \%$ & $24.00 \%$ \\
\hline 0.9 & 7 & 0.090968 & 581.768 & $76.73 \%$ & $32.07 \%$ & $24.60 \%$ \\
\hline 1 & 7 & 0.088790 & 566.235 & $78.00 \%$ & $32.32 \%$ & $25.21 \%$ \\
\hline 1.1 & 6.7 & 0.087024 & 550.230 & $79.40 \%$ & $32.39 \%$ & $25.72 \%$ \\
\hline 1.2 & 6.2 & 0.085650 & 533.707 & $80.93 \%$ & $32.29 \%$ & $26.13 \%$ \\
\hline 1.3 & 5.9 & 0.084229 & 519.180 & $82.32 \%$ & $32.28 \%$ & $26.57 \%$ \\
\hline 1.4 & 5.6 & 0.082958 & 505.260 & $83.70 \%$ & $32.23 \%$ & $26.98 \%$ \\
\hline 1.5 & 5.3 & 0.081832 & 491.835 & $85.08 \%$ & $32.15 \%$ & $27.35 \%$ \\
\hline
\end{tabular}

Table 3. Optimized TurboAux Engine Configuration and Corresponding Results

\begin{tabular}{|c|c|c|c|c|c|c|}
\hline Bypass Ratio & ABPR & $\begin{array}{c}\text { TSFC } \\
\left(\mathrm{kg} / \mathrm{N}^{*} \mathrm{hr}\right)\end{array}$ & $\begin{array}{c}\text { Fs } \\
\left(\mathrm{N}^{*} \mathrm{~s} / \mathrm{kg}\right)\end{array}$ & $\begin{array}{l}\text { Propulsive } \\
\text { Efficiency }\end{array}$ & $\begin{array}{c}\text { Thermal } \\
\text { Efficiency }\end{array}$ & $\begin{array}{c}\text { Overall } \\
\text { Efficiency }\end{array}$ \\
\hline 0.1 & 7 & 0.129998 & 868.331 & $59.48 \%$ & $28.94 \%$ & $17.22 \%$ \\
\hline 0.2 & 7 & 0.137441 & 896.059 & $58.46 \%$ & $27.86 \%$ & $16.28 \%$ \\
\hline 0.3 & 7 & 0.1436147 & 918.070 & $57.69 \%$ & $27.01 \%$ & $15.58 \%$ \\
\hline 0.4 & 7 & 0.1488337 & 935.942 & $57.10 \%$ & $26.33 \%$ & $15.04 \%$ \\
\hline 0.5 & 7 & 0.1533048 & 950.770 & $56.63 \%$ & $25.78 \%$ & $14.60 \%$ \\
\hline 0.6 & 7 & 0.1571718 & 963.330 & $56.24 \%$ & $25.32 \%$ & $14.24 \%$ \\
\hline 0.7 & 7 & 0.1605389 & 974.182 & $55.91 \%$ & $24.94 \%$ & $13.94 \%$ \\
\hline 0.8 & 7 & 0.1634849 & 983.736 & $55.62 \%$ & $24.61 \%$ & $13.69 \%$ \\
\hline 0.9 & 7 & 0.1660716 & 992.291 & $55.36 \%$ & $24.34 \%$ & $13.48 \%$ \\
\hline 1 & 7 & 0.1683487 & 1000.068 & $55.13 \%$ & $24.12 \%$ & $13.29 \%$ \\
\hline 1.1 & 6.7 & 0.1710977 & 1005.445 & $55.01 \%$ & $23.78 \%$ & $13.08 \%$ \\
\hline 1.2 & 6.2 & 0.1743308 & 1008.312 & $55.02 \%$ & $23.34 \%$ & $12.84 \%$ \\
\hline 1.3 & 5.9 & 0.1770197 & 1011.313 & $54.99 \%$ & $22.99 \%$ & $12.64 \%$ \\
\hline 1.4 & 5.6 & 0.1797008 & 1013.292 & $55.00 \%$ & $22.65 \%$ & $12.45 \%$ \\
\hline 1.5 & 5.3 & 0.182405 & 1014.266 & $55.04 \%$ & $22.29 \%$ & $12.27 \%$ \\
\hline
\end{tabular}


Table 4. Performance Percentages

\begin{tabular}{|c|ccccc|}
\cline { 2 - 6 } \multicolumn{1}{c|}{} & TSFC & Fs & $\begin{array}{c}\text { Propulsive } \\
\text { Efficiency }\end{array}$ & $\begin{array}{c}\text { Thermal } \\
\text { Efficiency }\end{array}$ & $\begin{array}{c}\text { Overall } \\
\text { Efficiency }\end{array}$ \\
\hline Turbofan & $-29 \%$ & $-38 \%$ & $+35 \%$ & $+5 \%$ & $+42 \%$ \\
\hline TurboAux & $+40 \%$ & $+17 \%$ & $-7 \%$ & $-23 \%$ & $-29 \%$ \\
\hline
\end{tabular}

The results presented in the previous section model the performance of the novel TurboAux engine in comparison to a conventional turbofan engine. In the conventional low-bypass turbofan engine, a few trends became apparent. As bypass ratio increased, TSFC decreased at a significant cost to Fs, but propulsive, thermal, and overall efficiency increased as expected. This is illustrated in Fig. 4. Conversely, in the TurboAux, as bypass ratio increased, TSFC increased as did Fs, but all three efficiencies decreased. These trends are illustrated in Fig. 3. It is apparent that the augmentation of an auxiliary combustion chamber in the bypass stream of a low-bypass turbofan engine will significantly increase the thrust capabilities of the engine at the cost of increased fuel consumption and lower efficiency. As bypass ratio increased, the turbofan model resulted in a $29 \%$ decrease in TSFC and a $38 \%$ decrease in Fs, but the overall efficiency increased by $42 \%$. The TurboAux model showed a $40 \%$ increase in TSFC and a $17 \%$ increase in Fs, but the overall efficiency suffered a $29 \%$ decrease. Figure 5 further illustrates the performance of these engines compared to one another.

\section{Conclusion and Future Work}

The increase of bypass ratio in a low-bypass turbofan engine lowers TSFC and increases overall efficiency but at the cost of a significant loss in Fs. The premise of this research and the conception of this novel engine design (TurboAux engine) aims to investigate the possibility of considerably increasing the thrust capability of an engine while keeping the fuel consumption steady and manageable. The results presented show that while Fs is increased, so is TSFC. Applications for this engine should be considered in scenarios where lowering fuel consumption is not the primary objective as is the case with commercial flights. This subsonic novel engine makes the case for its application in charter aircraft and close-air-support aircraft as well as a myriad of other applications.

As part of the future work, the authors are working on studying the implementation of a TurboAux engine in aircrafts with engines whose capacities are comparable. The authors are also studying the TurboAux engine as an alternative to a turbojet or turbofan engine with an afterburner. These results will be presented as a journal publication of the TurboAux engine.

\section{References}

[1] Raymer, D.P., Aircraft Design: A Conceptual Approach, 5th ed., AIAA Education Series; American Institute of Aeronautics \& Astronautics: Reston, VA, USA, 2012.

[2] MacIsaac, B., and Langston, R., Gas Turbine Propulsion Systems, 1st ed., Wiley: Hoboken, NJ, USA, 2011.

[3] Cohen, H., Rogers, G.F.C., and Saravanamuttoo, H.I.H., Gas Turbine Theory, 3rd ed., John Wiley \& Sons, New York, 1987, Chap. 3.

[4] Asundi, S.A., and Ali, S.F., "Parametric Study of a Turbofan Engine with an Auxiliary High-Pressure Bypass," International Journal of Turbomachinery, Propulsion and Power, Vol 4, No. 1, Jan 2019

[5] Campbell, A.S., Thermodynamic Analysis of Combustion Engines, $1^{\text {st }}$ ed., Wiley: Hoboken, NJ, USA, 1979.

[6] Hill, P., and Peterson, C., Mechanics and Thermodynamics of Propulsion, $2^{\text {nd }}$ ed., Prentice Hall, USA, 1992. 